\title{
Assessment of Biodegradation and Eco-Toxic Properties of Novel Starch and Gelatine Blend Bioplastics
}

\author{
Marta Mroczkowska ${ }^{1}$ (D) Kieran Germaine ${ }^{1}$, David Culliton ${ }^{2}$, Thomais Kakouli Duarte ${ }^{1}$ \\ and Adriana Cunha Neves ${ }^{1, *(\mathbb{D})}$ \\ 1 Department of Science and Health, Institute of Technology Carlow, R93 V960 Carlow, Ireland; \\ marta.mroczkowska@itcarlow.ie (M.M.); kieran.germaine@itcarlow.ie (K.G.); \\ thomae.kakouli@itcarlow.ie (T.K.D.) \\ 2 Department of Aerospace, Mechanical and Electronic Engineering, Institute of Technology Carlow, \\ R93 V960 Carlow, Ireland; David.Culliton@itcarlow.ie \\ * Correspondence: nevesa@itcarlow.ie
}

check for updates

Citation: Mroczkowska, M.; Germaine, K.; Culliton, D.; Kakouli Duarte, T.; Neves, A.C. Assessment of Biodegradation and Eco-Toxic Properties of Novel Starch and Gelatine Blend Bioplastics. Recycling 2021, 6, 81. https://doi.org/10.3390/ recycling 6040081

Academic Editors: Michele John and Wan-Ting (Grace) Chen

Received: 22 October 2021

Accepted: 29 November 2021

Published: 16 December 2021

Publisher's Note: MDPI stays neutral with regard to jurisdictional claims in published maps and institutional affiliations.

Copyright: (C) 2021 by the authors Licensee MDPI, Basel, Switzerland. This article is an open access article distributed under the terms and conditions of the Creative Commons Attribution (CC BY) license (https:// creativecommons.org/licenses/by/ $4.0 /)$.

\begin{abstract}
To combat the release of petroleum-derived plastics into the environment the European Commission has adopted the EU plastics strategy, which aims for a complete ban on single-use plastics by 2030. Environmentally friendly and sustainable packaging like bioplastic is being up taken at significant levels by companies and consumers. In this study, the environmental impact of novel gelatine-starch blend bioplastics is investigated. The assessments included ecotoxicology with different species that can be found in marine and soil environments to simulate natural conditions. Microalgae, plant, and nematode species were chosen as these are representative of their habitats and are known for their sensitivity to pollutants. Degradation rates of these novel bioplastics were assessed as well as microbiome analysis of the soil before and after bioplastic degradation. The main findings of this study are that (i) the bioplastic generated can be fully biodegraded in soil environments at moderate conditions $\left(20^{\circ} \mathrm{C}\right)$ leaving no physical traces; (ii) bioplastic did not exhibit significantly adverse effects on any organisms assessed in this study; (iii) microbiome analysis of the soil after biodegradation showed a decrease in alpha diversity and a significant increase of Actinobacteria and Firmicutes phyla, which were dominative in the soil.
\end{abstract}

Keywords: bioplastics; fish protein; biodegradation; ecotoxicity

\section{Introduction}

Plastics are used in many industries and generate enormous amounts of waste [1]. The majority of these plastics are polymers such as polyethylene, polypropylene, polystyrene, polyethylene terephthalate. These are derived from fossil hydrocarbons and are rarely biodegradable, and so they have major impacts on the environment. Although the consequences of plastic accumulation in the environment have been known for decades, plastic production is still growing. From 1950 through to 2015, 7.8 billion tons of plastic were produced, over half of which was produced in the past 13 years. In 2015, 380 million metric tons $(\mathrm{Mt})$ of plastic resins and fibers were produced worldwide [1]. Plastic waste can be recycled and converted into a secondary material, which delays but does not fully avoid final disposal. The plastic that cannot be recycled is incinerated or disposed in landfills [2]. Plastic pollution has been widely documented through numerous studies looking at plastic pollution in land and aquatic environments [3] and interfering with the fauna and flora in these habitats. Romeo et al. (2015) presented evidence that plastic additives such as phthalates, nonylphenol, and bisphenol from ingested plastics have negative effects on the reproductive system in bluefin tuna (Thunnus thynnus) [4]. This not only influences bluefin tuna populations and other species in this ecosystem, but it also threatens food security (Romeo et al., 2015 [4]; Gall and Thompson, 2015 [5]). 
Bioplastic generated from non-toxic raw materials like starch and protein that can fully degrade will not leave a legacy of environmental damage to the same extent as non-biodegradable plastic. The exact extent to which plastic pollution affects natural environments can only be estimated. In a study by Jambeck et al., from 2015, it was estimated that in 2010, 192 coastal countries produced 275 Mt of plastic waste of which 4.8-12.7 Mt had entered the ocean [2]. Plastic packaging accounts for $50 \%$ of the plastic waste that is produced worldwide; high-income countries produce more plastic waste but in middle and low-income countries more plastic waste ends up in the environment due to mismanagement [6].

Alternatives to fossil-fuel-based plastics are gaining interest due to growing public awareness of the plastic pollution problem as well as actions taken by governments to tackle plastic pollution. Since China's import ban in January 2018, the import of non-industrial plastic waste has been prohibited. This led to a crisis in the global plastic recycling industry and the accumulation of plastic waste in landfills [7]. As a consequence, the destinations for plastic waste have been altered to countries like Malaysia, Indonesia, Thailand, and the Philippines where there is a lack of waste management legislation and open burning is a common practice [8]. The European Union has developed a plastics strategy that aims to protect our environment and reduce marine litter, greenhouse gas emissions, and our dependence on imported fossil fuels. It aims to support more sustainable and safer consumption and production patterns for plastics and to transform the way plastic products are designed, produced, used, and recycled in the EU [9]. Bioplastics based on renewable raw materials are regarded as a promising alternative for single-use packaging, and a possible solution to reduce plastic production [10]. Biodegradation is a natural process driven by microorganisms that feed on the material and results in breaking it down; this process is vital for nutrients and energy recycling [11].

Although biodegradable plastics were only introduced to the market in the 1990s, they remain peripheral in terms of adoption and usage. Only $1 \%$ of the plastic produced every year falls into the bioplastic category. This is due to their high cost, lack of market demand, and material versatility, but also due to lack of education and gaps in legislation [12]. The use of novel renewable raw materials that can generate cheap, durable, and functional bioplastics that match the physio-chemical characteristics of petroleum-based plastics is fundamental for the further adoption of bioplastics in mainstream packaging [13].

Renewable raw materials that are commonly used in the bioplastic industry include proteins, starch, and other food-related substances. Therefore, by-products from the food industry can be ideal raw materials for generating bioplastics. One of the proteins used in the generation of starch-protein blend bioplastics is gelatine, due to its film-forming properties [14]. Moreover, adding proteins to starch-based bioplastics has shown to lead to better mechanical and physio-chemical properties. Gelatine can be easily obtained by heat treatment of collagen, which is a structural protein found in animal connective tissue. By-products from the meat industry such as skins, offal, and bones are mainly composed of connective tissue rich in collagen and are an ideal source of gelatine [15].

However, proteins sourced from porcine and bovine gelatines are, notionally, associated with diseases such as foot-and-mouth disease and bovine spongiform encephalopathy (BSE). Moreover, products generated with mammalian gelatine might not be acceptable for socio-cultural reasons. Therefore, alternative sources of gelatine such as piscine (fish) gelatine might be of interest to the market $[16,17]$. Piscine gelatine, however, differs from mammalian gelatine in its rheological properties and shows less stability as a polymer. This can be a drawback for the use of this source of gelatine for some industries; but, it may have the potential for the generation of different starch-gelatine blend bioplastics with different mechanical and physio-chemical properties, compared to those generated with porcine or bovine gelatine. To the best of our knowledge, there are no studies to date investigating how bioplastics generated with piscine gelatine impact the environment compared with bioplastics generated with bovine or porcine gelatine. For that reason, the objectives of this study are (a) to generate starch-protein blend bioplastics using gelatine from three 
different sources (piscine, porcine and bovine), (b) to determine the degradation time of the bioplastics generated, and (c) to assess the environmental safety of the bioplastics, in a laboratory setting simulating aquatic and terrestrial environments.

\section{Materials and Methods}

\subsection{Materials}

Potato starch (MP BIomedicals LLC, Amsterdam, The Netherlands), food-grade piscine gelatine, 200 bloom (Louis Francois, Croissy-Beauboufg, France) porcine gelatine, 130 bloom (ACROS Organics, Vantaa, Finland), and bovine gelatine, 250 bloom (VWR Chemicals, VWR International, Radnor, PA, USA) were used to generate bioplastics. Glycerol (EMPROVE ${ }^{\circledR}$ bio, Merck KGaA, Darmstadt, Germany) was used as plasticiser. Standard soil used for biodegradation was made from locally bought, sand (Westland, Play Sand, Yeovil, Somerset, UK), compost (Westland, Multi-Purpose Compost), kaolinite, natural (SIGMA-ALDRICH, Taufkirchen, Germany) and natural soil collected from grass pitch located on IT Carlow grounds. Potassium dihydrogen phosphate $\left(\mathrm{KH}_{2} \mathrm{PO}_{4}\right)$, magnesium sulphate $\left(\mathrm{MgSO}_{4}\right)$, sodium nitrate $\left(\mathrm{NaNO}_{3}\right)$, urea $\left(\mathrm{CH}_{4} \mathrm{~N}_{2} \mathrm{O}\right)$, ammonium chloride $\left(\mathrm{NH}_{4} \mathrm{Cl}\right)$, and n-allythiourea $\left(\mathrm{H}_{2} \mathrm{C}=\mathrm{CHCH}_{2} \mathrm{NHCSNH}_{2}\right)$ were added to soil used for biodegradation. Anhydrous $\mathrm{NaOH}$ was used in the OxiTop chambers. Cellulose filters (MACHEREY-NAGEL, Dueren, Germany) were used as a positive control in the biodegradation experiment. For the microalgae test, the Algaltox ${ }^{\mathrm{TM}}$ kit (MicroBioTests Inc., Ghent, Belgium) was used, and for the plant phototoxicity test, the Phytotox kit (MicroBioTests Inc., Ghent, Belgium) was used, which provided all necessary materials. Top soil (Westland, Top Soil, Yeovil, Somerset, UK) was used for the ecotoxicology studies using nematodes. The Steinernema feltiae strain SB12(1) [18] was obtained from the IT Carlow nematode stock culture and Galleria mellonella were sourced commercially from Live Foods Direct (Sheffield, UK). Deoxyribonucleic acid (DNA) extractions were performed using the DNeasy ${ }^{\circledR}$ PowerSoil ${ }^{\circledR}$ Pro-Kit (QIAGEN, Hilden, Germany).

\subsection{Formulation of the Bioplastics}

The bioplastics used in this study were prepared as described in Mroczkowska et al. (2021) with gelatines from three different sources, piscine, porcine, and bovine [19].

\subsection{Degradation Tests}

Degradation studies were performed in soils using the OxiTop ${ }^{\circledR}$ soil respiration chambers according to ISO 17556:2012 with some modifications. The OxiTop ${ }^{\circledR}$ system is based on the principle that $\mathrm{CO}_{2}$ production is proportional to the quantity of the degraded organic compounds under study and it is the measure of biological oxidation. This system is suitable for monitoring biodegradation for organic compounds, such as bioplastics in soil. The OxiTop ${ }^{\circledR}$ measuring head measures and stores data, which are measured as pressure. When oxygen is consumed in a closed vessel at a constant temperature, emerging $\mathrm{CO}_{2}$ is absorbed by $\mathrm{NaOH}$ that is in a plastic beaker in the vessel and a negative pressure develops. This pressure drop is proportional to sequestrated $\mathrm{CO}_{2}$ [20]. Standard soil used for bioplastic degradation was prepared according to ISO 17556:2012 Standard [21].

The water holding capacity and soil $\mathrm{pH}$ was measured before the degradation test and the water content of the soil was adjusted to $50 \%$ of the soil total water holding capacity. Then, $200 \mathrm{~g}$ of standard soil was added to each chamber and $2.5 \mathrm{~g}$ of either piscine, porcine, or bovine bioplastic was added. Two controls were used in the experiment: a negative control consisting of soil with no bioplastic and a positive control consisting of $2.5 \mathrm{~g}$ of cellulose filters. The following nutrient solutions were added to each chamber and the water content of the soil was adjusted: potassium dihydrogen phosphate $(0.2 \mathrm{~g} / \mathrm{kg}$ of soil), magnesium sulphate $(0.1 \mathrm{~g} / \mathrm{kg}$ of soil), sodium nitrate $(0.4 \mathrm{~g} / \mathrm{kg}$ of soil), urea $(0.2 \mathrm{~g} / \mathrm{kg}$ of soil) and ammonium chloride ( $0.4 \mathrm{~g} / \mathrm{kg}$ of soil). To prevent nitrification and the generation of nitrous oxide gases, n-allythiourea was added at a concentration of $50 \mathrm{mg} / \mathrm{kg}$ of standard soil. Then, $10 \mathrm{~g}$ of anhydrous $\mathrm{NAOH}$ were placed into a plastic beaker and placed on the 
holding stage below the measuring head. OxiTop-C measuring heads were fitted onto the chambers containing test material and soil with moisture content adjusted to $50 \%$ of soil water holding capacity. Samples were started using the OxiTop handheld controller. Closed chambers were kept at $20^{\circ} \mathrm{C}$ in darkness. Degradation tests were carried out in triplicate. Measurements were taken continuously every $6 \mathrm{~h}$ for 54 days. Once the pressure in the chamber dropped below $-100 \mathrm{hPa}$, all chambers were ventilated in order to return the chamber to atmospheric pressure and placed back into the incubation oven.

\subsection{Microalgae Toxicity}

The toxicity of the bioplastics to marine microalgae (Phaeodactylum tricornutum) was assessed using the commercially available Algaltox ${ }^{\mathrm{TM}}$ kit following the manufacturer's instructions. Microalgae were pre-cultured in culturing medium without shaking prior to the test for 5 days at $25^{\circ} \mathrm{C}\left( \pm 2{ }^{\circ} \mathrm{C}\right)$ with illumination. Then, $5 \mathrm{~g}$ of each bioplastic were dissolved in $100 \mathrm{~mL}$ volumetric flasks with culturing medium and made up to the mark, and $10 \mathrm{~mL}$ of the bioplastic suspension were transferred into test vials and inoculated with $1 \mathrm{~mL}$ of pre-cultured microalgae. Flasks without bioplastics acted as negative controls. Initial optical density (OD) was measured at $670 \mathrm{~nm}$ in a spectrophotometer. OD results were taken throughout the 9 days of the experiment and final readings were used to determine the statistical difference between treatments. Before each measurement test, the vials were shaken to resuspend microalgae cells evenly.

\subsection{Nematode Toxicity}

Petri dishes $(9 \mathrm{~cm})$ were lined with filter paper. Approximately $1-1.5 \mathrm{~mL}$ of a dense infective juvenile (IJ) suspension was applied to the filter paper until it was moist. Five G. mellonella larvae were placed onto the filter paper and incubated for 3-10 days until insect mortality occurred. Once insect mortality had occurred, nematode IJ were recovered according to White from 1927 [22]. A raised platform was created by placing filter paper over a $3.5 \mathrm{~cm}$ Petri dish in a transparent container, and $50 \mathrm{~mL}$ of deionised water was added to submerge the edges of the filter paper. The infected insects were placed onto the platform and incubated for up to 14 days. Nematodes exiting the insect cadavers entered the water reservoir via the moist filter paper, and IJ were harvested by decanting the water into an empty transparent dish. Pots containing $500 \mathrm{~g}$ of commercially available soil (Westland, Topsoil) received $6.25 \mathrm{~g}$ of either piscine, porcine, or bovine bioplastic. The negative control consisted of soil with no bioplastic. For comparison purposes, another treatment consisting of $6.25 \mathrm{~g}$ of polylactic acid (PLA) plastic was set up. First, $2000 \mathrm{IJ}$ were added to each pot in a water volume to provide $10 \%$ moisture. Treatments were carried out in 6 replicates. After 4 weeks, $5 \mathrm{~g}$ soil samples were taken from each pot in triplicate and two G. mellonella larvae were exposed to each soil sample until insect mortality. The two sublethal toxicity endpoints regarding the effect of bioplastics on nematodes were (1) the ability of the nematodes to kill their insect hosts and (2) nematode reproduction after exposure to bioplastics in the soil. Insect mortality was easily recorded visually and nematode reproduction was observed via placing the dead insect in traps as described above. Recovered IJ numbers were estimated by counting IJ under a stereoscope on a graded Petri dish in $250 \mu \mathrm{L}$ of deionised water.

\subsection{Assessment of Phytotoxicity}

To assess whether the bioplastics had any phytotoxic effect they were tested against three plant species Sorghum saccharatum (Sorgho, a representative monocot), Lepidium sativum (Cress, a dicot species), and Sinapis alba (Mustard, a dicot species). The experiments were carried out in the soil. The water holding capacity of the soil was determined to adjust the water content of the soil to $50 \%$ of the soil total water holding capacity. In a glass funnel with cotton wool, $50 \mathrm{~g}$ of test soil were hydrated with $50 \mathrm{~mL}$ of deionised water. Water was left to drip into a graduated cylinder over $24 \mathrm{~h}$. The water retained by the soil was used to calculate the $\%$ water holding capacity. Then, $1.25 \mathrm{~g}$ of bioplastic per $100 \mathrm{~g}$ of soil was 
added and allowed to degrade over 3 weeks period until no visible bioplastic pieces were visible. Plates were filled with $100 \mathrm{~g}$ of test soil in the lower compartment of the two-part plates, hydrated with $10 \mathrm{~mL}$ of deionised water, the black filter paper was placed on top of the soil, and finally, 10 seeds of the same test plant were placed on top of the filter paper. Plates were incubated at $25^{\circ} \mathrm{C}$ in darkness for $72 \mathrm{~h}$, after which seed germination rates and root lengths were measured. Pots without bioplastics served as controls.

\subsection{Soil Microbiome Analysis}

To assess if the presence of bioplastics in the soil had any negative effects on the soil microbial biodiversity, microbiome analysis was carried out on soil samples incubated with the bioplastics. The soil used in the biodegradation (Oxitop) experiment was used for this analysis. Soil samples were taken before and after bioplastic degradation (54 days). DNA was extracted from $250 \mathrm{mg}$ of soil samples using the DNeasy ${ }^{\circledR}$ PowerSoil ${ }^{\circledR}$ Pro Kit. Four DNA extractions were performed from the soil before bioplastic biodegradation and four DNA extractions from the soil 52 days after piscine bioplastic was added. The sequence data was submitted to the NCBI database under Bioproject number These DNA samples were sent to a commercial DNA sequencing company for library preparation and sequencing (Novogene, UK). PRJNA759397 and accession numbers SRR15698719 to SRR15698726.

\subsection{Statistical Analysis}

The results were analysed by one-way analysis of variance (ANOVA) at significance level $p \leq 0.05$, and a post hoc test, Tukey's honest significant difference test followed by Shapiro-Wilk to determine the normal distribution of data was used. SPSS Statistics (IBM SPSS Statistics 2015, New York, NY, USA) and Excel 2016 (Microsoft Excel 2016, San Francisco, CA, USA) was used for statistical analysis.

\section{Results and Discussion}

\subsection{Formulation of the Bioplastics}

The bioplastics produced for this work were visually semi-transparent, homogenous, bright, and easily removed from the drying moulds. Colour differences among different bioplastics generated were noted by visual inspection. The bioplastic generated from piscine gelatine was less yellow in colour than bioplastic generated from pork or bovine gelatine. This can be of significance when it comes to the application of the bioplastic [12]. The colour difference among bioplastic generated from piscine, porcine, and bovine gelatine are due to differences in rheological properties caused by the different amino acid composition of each gelatine. Rheological properties are greatly influenced by proline and hydroxyproline content. It has been reported in the literature that mechanical properties of films based on gelatines from piscine, porcine, and bovine sources are influenced by gelatine type, and these properties include colour and water solubility [23].

\subsection{Soil Respiration Tests}

In order to test the biodegradation capacity of the bioplastics, soil respiration experiments were set up using the Oxitop ${ }^{\circledR}$ mannometric measuring chambers. Degradation tests show (Figure 1) that bioplastic generated with piscine gelatine and starch were fully degraded by microorganisms in the soil within 52 days, although the bioplastic was not visible to the naked eye much earlier in the experiment. After 54 days when the readings for the bioplastics stabilised (i.e., no further $\mathrm{CO}_{2}$ was generated) the experiment was successfully finished. At this point, the cellulose filters that were used as reference material were not fully degraded and were visible to the naked eye after 50 days, while still producing $\mathrm{CO}_{2}$. Bioplastic generated with porcine and bovine gelatine showed similar degradation rates and fully degraded within 66 days. After that, the readings stabilised and no further drop in pressure was noted. 


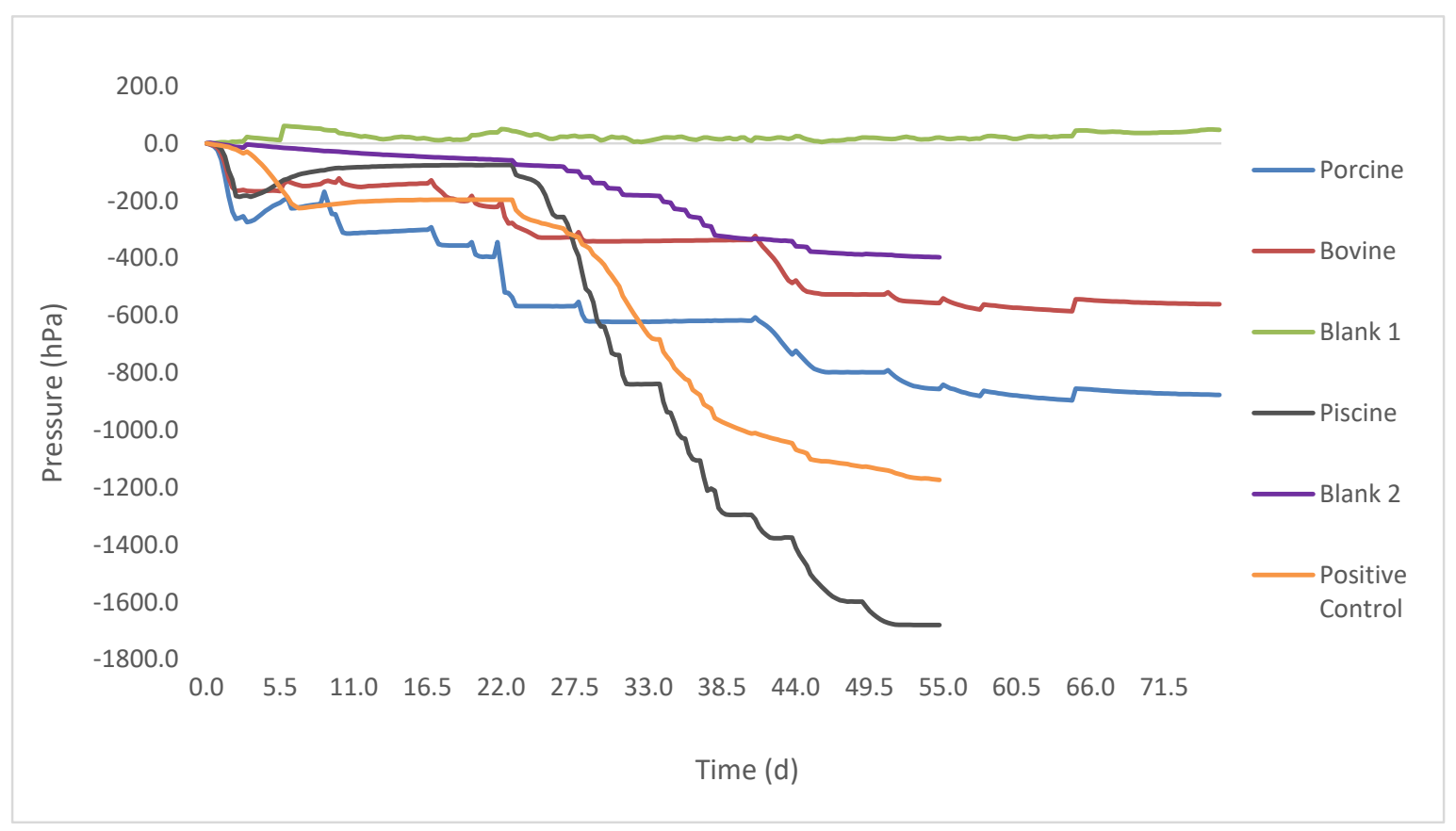

Figure 1. Pressure drops measured by Oxitop chambers of soil with bioplastic made from different gelatines. Blank 1 is a blank corresponding to porcine and bovine sample. Blank 2 is a blank corresponding to piscine and positive control, as they ran at two different times. Cellulose was used as positive control $(n=3)$.

\subsection{Microalgae Toxicity}

The bioplastics were assessed in the lab to determine their effects on the growth of marine microalgae. Microalgae are commonly used as indicators of environmental pollution. They are found in freshwater and saltwater where they are the main primary producers at the base of the food chain. Any disturbance of the microalgae population will have an effect on the whole ecosystem [24]. Microalgae growth was observed in all treatments (Figure 2). All treatments with bioplastics had greater growth than the control without bioplastic. This is evidence that the bioplastics have no negative effect on microalgae growth. Statistical analysis $(p$-value $=0.05$ ) showed that all treatments with bioplastics caused significantly higher growth of microalgae compared to the control. This was an expected outcome, since the addition of bioplastic that is made from starch and protein enriches the culture media with additional carbon $(\mathrm{C})$, nitrogen $(\mathrm{N})$, and phosphorus $(\mathrm{P})$, allowing increased microalgae growth.

The concentrations of the nutrients coming from the bioplastics in these vessels are considerably higher than those that would be found in natural aquatic ecosystems, where significant dilution would occur. Therefore, the risk of eutrophication of water bodies due to bioplastics is low. We deliberately used high concentrations of bioplastics so as to detect possible inhibitory effects on microalgae growth and the results show the bioplastics had no negative effects on marine micro-algae growth. A study by Sforzini et al. (2016) investigated the ecotoxicity of bioplastic (Mater-Bi is a family of biodegradable and compostable plastics made from renewable raw material like starches, cellulose, and vegetable oils) and, similarly, as in our study, selected organisms such as microalgae, plants, and protozoa were used to determine possible ecotoxicity [25]. The study by Sforzini et al. (2016) found no negative effect of their bioplastic on microalgae, which agrees with findings in the present study [25]. The microalgae, however, did not experience increased growth as occurred in the present study, which can be due to differences in bioplastic composition. 


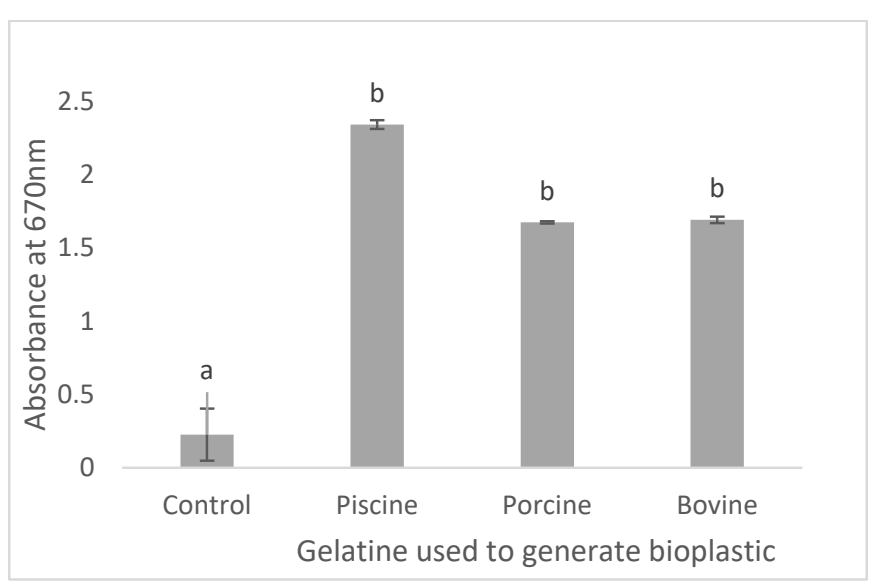

Figure 2. Microalgae (Phaeodactylum tricornutum) growth in aqueous solution with different bioplastic treatments. Absorbance at $670 \mathrm{~nm}$ represents the density of the solution directly related to microalgae growth ( $n=3$, error bars represent standard deviation, lowercase letters represent significantly different values).

\subsection{Nematode Toxicity}

To assess the possible effects of bioplastics on soil microfauna, they were tested against the soil nematode Steinernema feltiae. Nematodes are one of the world's most numerous organisms and have been frequently used in studies as bioindicators of environmental change, including soil contamination [26]. Steinernema feltiae SB12(1) is an entomopathogenic nematode that commonly occurs in Irish soils. It is therefore ideal for this part of the study, which aims to investigate any possible toxic effect of the bioplastic generated, in a laboratory-set microcosm that simulates the soil environment. There was an increased number of IJ recovered from the soils with bioplastics compared to the control soils, except the soil with piscine bioplastic. Statistical analysis of the results relating to nematode reproduction shows a significant difference between the piscine gelatine and the bovine gelatine (Figure 3).

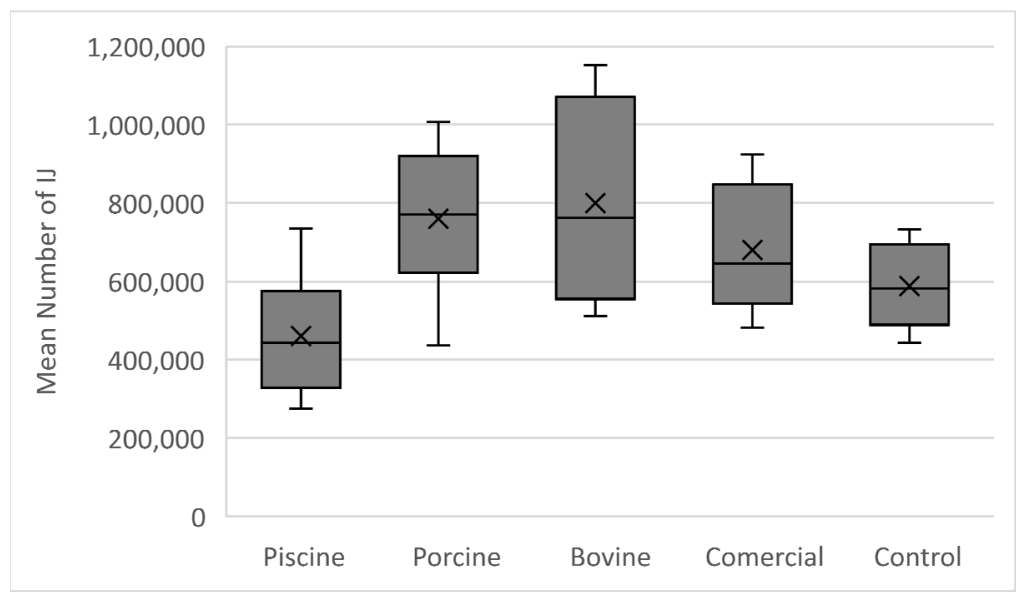

Figure 3. Mean $( \pm \mathrm{SE})$ number of IJ recorded per $1.8 \mathrm{~g}$ of waxworms emerging in the various bioplastic treated microcosms $(n=6$, error bars represent standard deviation).

The amino acid composition, especially proline and hydroproline, differs between gelatines from different sources. Differences in the amino acid composition result in physico-chemical differences between bioplastics [19] and these can interfere with the nematodes' life cycle by influencing the water layer around soil particles where nematodes naturally live. This could be a possible explanation as to why there was a significant difference in nematode response between piscine and bovine gelatine [27]. This study 
shows that although none of the treatments are significantly different from the controls, there are differences among bioplastics generated from piscine and bovine gelatine, with bovine gelatine having a significantly greater increase in the IJ recovered.

None of the bioplastics impaired the ability of the nematodes to infect and kill their hosts and to reproduce within (Figure 4). The nematodes' reproduction rate slowly depleted but there was an increase in nematodes' reproduction in all treatments at the last sampling. This sampling took place on 16 December and being the winter, it is possibility that the room temperature was affected due to high central heating and thus resulted in an increase in nematode reproduction in all treatments, as slightly higher temperature can positively affect nematode reproduction [28].

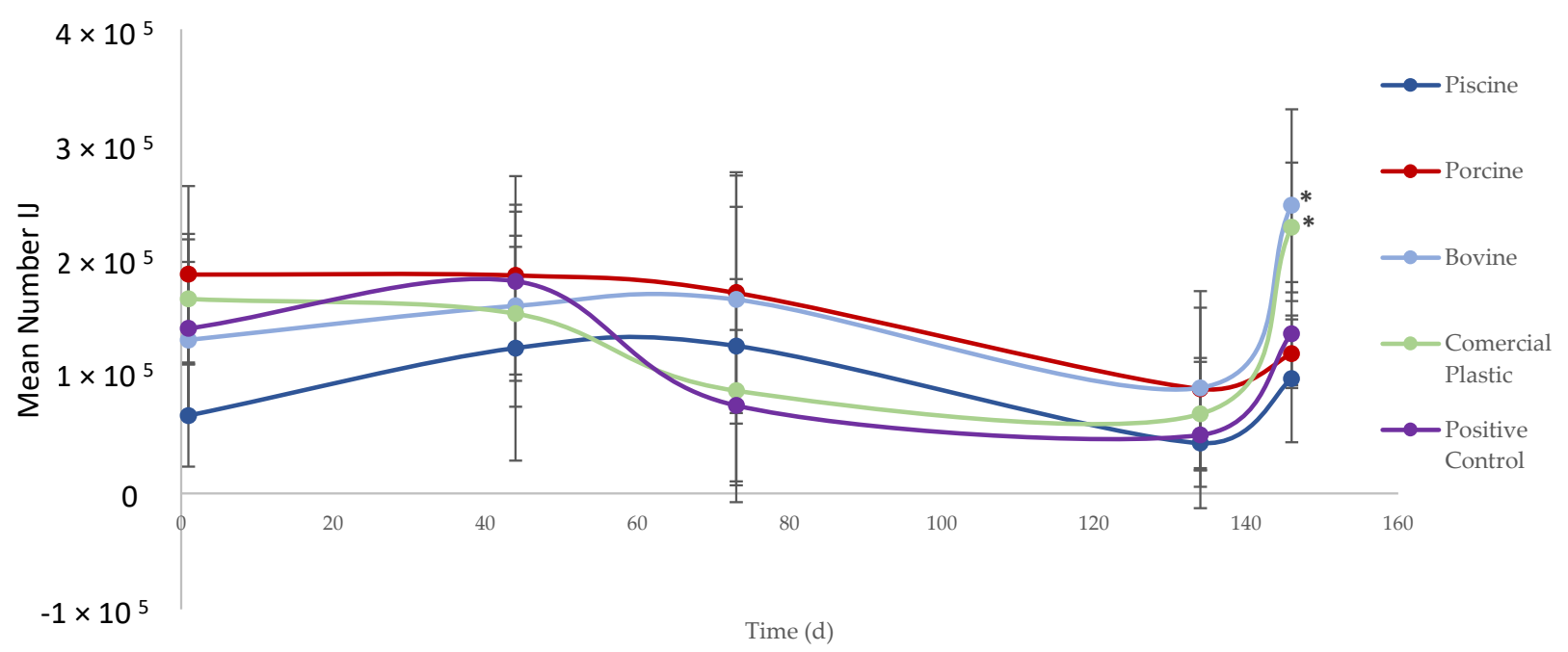

Figure 4. S. feltiae (SB12) reproduction rate in various bioplastic treated microcosms at five-time sampling points. Mean number of IJ recovered per $1.8 \mathrm{~g}$ of waxworms ( $\mathrm{n}=6$, error bars represent standard deviation).

\subsection{Seed Germination/Phytotoxicity}

The effect of plastic degradation in soil to plant systems have been reported due to the extensive use of bioplastics in agriculture as plastic mulch films [29]. However, the bioplastics currently used for this purpose are low-density polyethylene (LDPE) or linear low-density polyethylene (LLDPE) that do not fully degrade but instead are broken down into micro/nano-plastics [30].

To assess the possible effects of bioplastics on plant growth and development, they were tested against three different species of plants known to be very sensitive to toxins. Soil without added bioplastic was used as negative control (Figure 5). Data collected from mustard and cress seed germination tests were not normally distributed, therefore non-parametric Kruskal-Wallis tests were used to analyse it. A significant difference in the seed germination of cress was found between seeds that germinated in soil treated with bioplastic generated from bovine and porcine gelatine (Table 1).

Cress seeds that germinated in bovine bioplastic had significantly shorter root length compared to porcine bioplastic or control, suggesting a phytotoxic effect of bioplastic generated from bovine gelatine. Significant differences were found in mustard seeds in both porcine and piscine gelatine treatments compared to the control, suggesting a phytotoxic effect of these treatments on mustard seeds. In both piscine and porcine bioplastics treated soil, mustard seeds had significantly shorter root length in comparison to the control. Germination of sorgho seeds in the presence of the bioplastics showed no significant difference between any of the treatments and data generated were normally distributed. Data collected from sorgho seed germination suggest that none of the treatments have a negative effect on sorgho seed germination and are not phytotoxic to this plant species. Results collected from mustard and cress seed germination showed significant differences from positive control; the average root length was significantly shorter than the control 
average root length, suggesting a phytotoxic effect of the treatments. Differences in seed germination response derive from differences in the sensitivity of the plant species used.

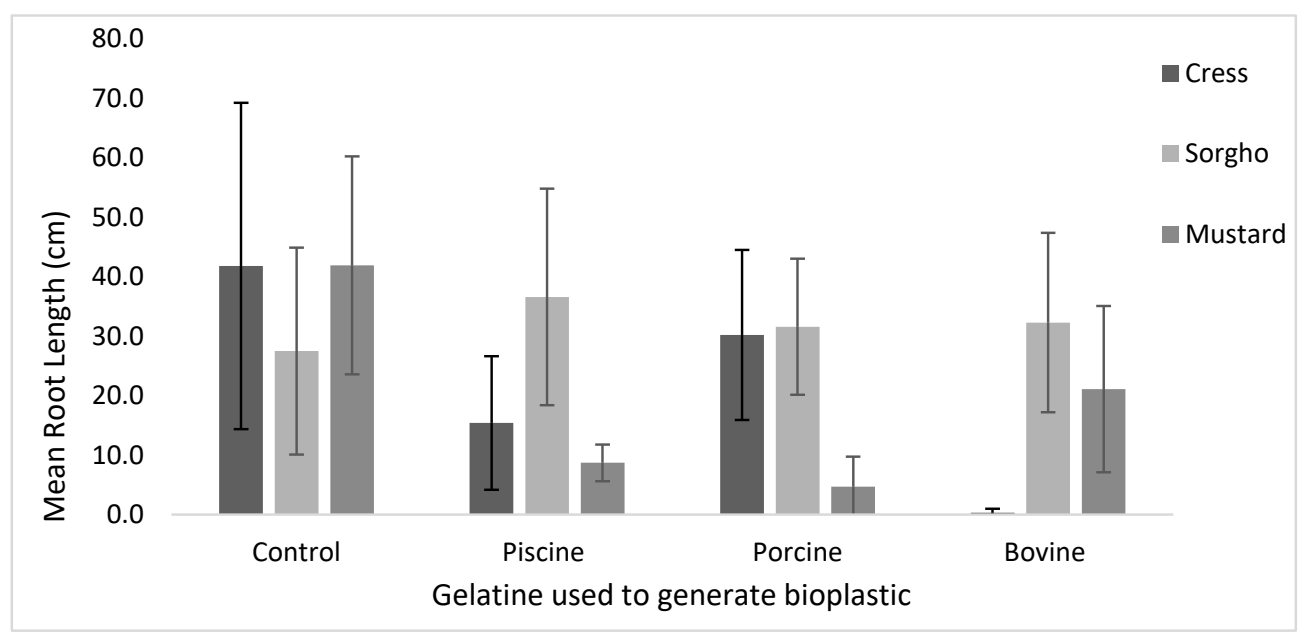

Figure 5. Effect of various bioplastics on the root length of three plants species $(n=10$, error bars represent standard deviation).

Table 1. Root length of seeds germinated in soil with different treatment $(n=10)$.

\begin{tabular}{ccccc}
\hline & \multicolumn{4}{c}{ Gelatine Type } \\
\hline Seed Type & Control & Piscine & Porcine & Bovine \\
\hline Cress & 41.8 & 15.4 & 30.2 & 0.3 \\
\hline Sorgho & 27.5 & 36.6 & 31.6 & 32.3 \\
\hline Mustard & 41.9 & 8.7 & 4.7 & 21.1 \\
\hline
\end{tabular}

The concentrations used in the experiment are purely experimental and there is a very low chance of reaching this concentration in the natural environment if the bioplastic was to be used on a large scale, but possible phytotoxic effect cannot be excluded. Depletion of $\mathrm{O}_{2}$ caused by microbes that degrade the bioplastic in the soil could lead to germination inhibition of the seeds as they require $\mathrm{O}_{2}$ for germination The bioplastic is hydrophilic in nature therefore it will absorb moisture from the soil, thus reducing the available water to the seeds and resulting in poorer germination. Glycerol is one of the ingredients of the bioplastic that has been shown to exhibit a phytotoxic effect on cocoa leaves by disrupting the normal function of plastids [31].

Other studies have shown that degradation of bioplastic can have adverse effects on seed germination, depending on the bioplastic additives [32], but to date, no other study has compared the effect of gelatine-based bioplastics on plant germination. In a study by Sforzini et al. (2016), plant germination was used to determine the ecotoxicity of bioplastic [25]. No negative effect of bioplastic on the germination of plants was found. Data presented by Sforzini et al. (2016) only described germination rate and not the root length as in our study [25]. The bioplastic used in our study exhibited a phototoxic effect on two of the used plants, mustard, and cress. To determine the exact cause of the phototoxic effect, more investigation is required. The concentration of the bioplastic in this experiment was $1.25 \%(w / w)$, which is significantly higher than $0.0063 \%$, which is the amount of plastic used when mulch film is applied on top of the soil [25]. Therefore, this phototoxic effect would possibly diminish when a smaller amount of bioplastic is applied to the soil.

\subsection{Microbial Soil Biodiversity}

To assess the possible effects of bioplastics on the soil bacterial communities, the microbiomes of the soil samples were analysed through metagenomic sequencing of the 
V3-V4 region of the bacterial $16 \mathrm{~S}$ ribosomal ribonucleic acid (rRNA) gene. DNA was extracted from four replicate soil samples treated with piscine bioplastic and four replicates of untreated (control) soil. The sequencing generated an average of 140,000 reads per sample, which was sufficient to cover $97 \%$ of the bacterial communities.

At the phylum level (Figure 6A), the control soil was dominated by Actinobacteria ( $42 \%$ relative abundance) followed by Proteobacteria (33\%), Firmicute $(6 \%)$, and Acidiobacteria (3\%). Together with six other phyla (with relative abundances between 1-3\%), they made up $99 \%$ of the bacterial microbiome within the control soil. Both Actinobacteria and Proteobacteria are bacterial phyla that are dominant in soil on a global scale [29].

A

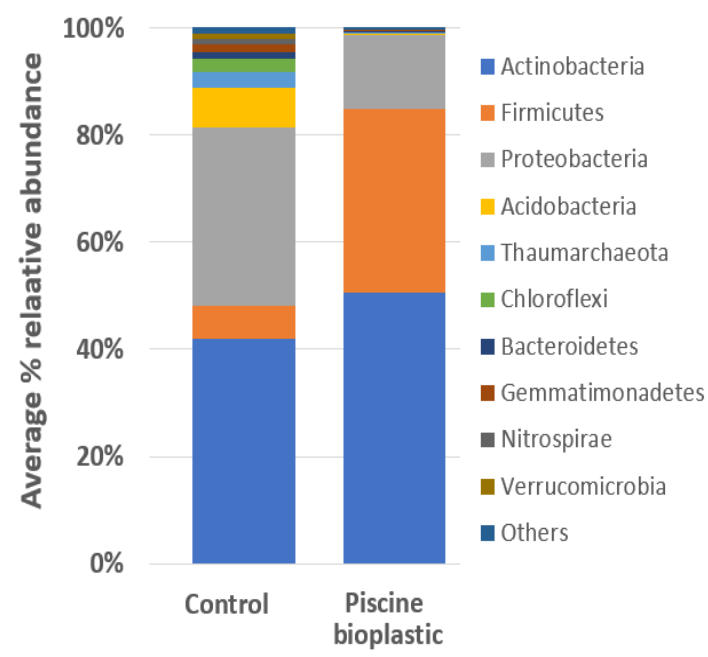

B

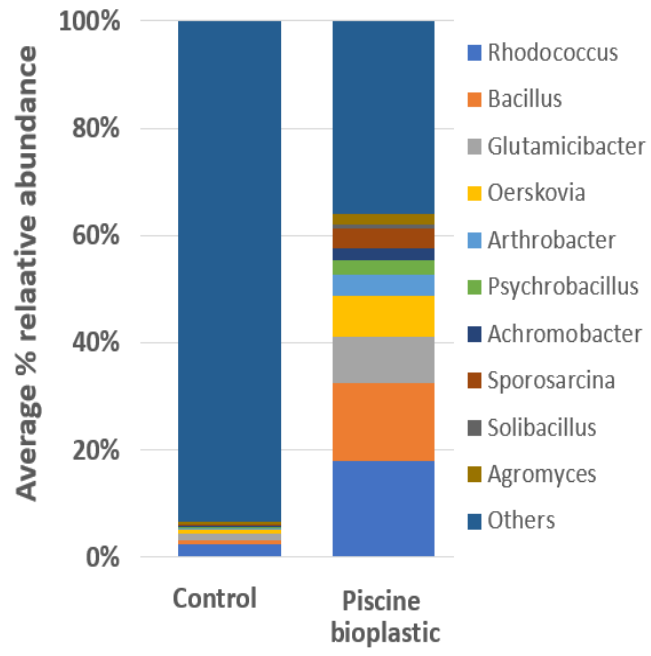

Figure 6. Top 10 phyla (A) and genera (B) identified in the control soil and the soil treated with piscine bioplastic based on $\%$ relative abundance $(n=4)$.

The introduction of the piscine bioplastic into the soil resulted in significant changes in the bacteria communities at the phylum in the soil. The most significant changes were increases in the relative abundances of Actinobacteria and Firmicutes, while all other phyla decreased in their relative abundances (by between 0.7-19\%). Actinobacteria increased from $42 \%$ to just over $50 \%$, but the largest increase was seen in the phylum Firmicutes, which increased from $6 \%$ in the control soil to over $33 \%$ in the bioplastic treated soil. Firmicutes is a phylum of bacteria whose species are associated with the degradation of biopolymers, specifically, ones from class Bacilli [33].

The relative abundance of phylum Acidobacteria decreased from 7 to $0.4 \%$. This phylum is the most abundant in soil worldwide [34], but in this specific soil the abundance was relatively low to start with but the introduction of the bioplastic resulted in an even bigger decrease. Acidobacteria are sensitive to $\mathrm{pH}$ changes, which may have had an influence on the relative abundance of this phylum [35]. In the control soil, the microbiome was dominated by genera such as Rhodococcus, Glutamicibacter, Gaiella, Mycobacterium, Pedomicrobium, Ilumatobacter, Mesorhizobium and Bradyrhizobium, each in relative abundances of between 1 and $2 \%$. Together these eight dominant genera made up about $6 \%$ of the control soils' microbiome. The remaining 403 genera identified in these control soils, had abundances of $0.0001-0.6 \%$ and represented $94 \%$ of the bacteria community. However, the introduction of the bioplastic resulted in significant increases in a small number of genera, most notably Rhodococcus and Bacillus, which increased in abundance from 2 to $21 \%$, and from 0.9 to $13 \%$, respectively. 
Other major winners were Glutamicibacter, Oerskovia, Arthrobacter, Psychrobacillus, Achromobacter, and Sporosarcina, whose abundances increased by up to $3 \%$. To a lesser extent, other genera also benefited from the presence of the bioplastic: Solibacillus, Agromyces, Ensifer, Paenibacillus, Pseudomonas, Citrobacter, Intrasporangium all increased in abundances to reach between $1-2 \%$ of the total microbiome. These 15 genera represented $72 \%$ of the soil microbiome in these samples. However, for the vast majority of the remaining 429 genera identified, there was a decrease in their abundance. There were 79 genera that were detected in the control soil samples but which were not detected in the soils incubated with the bioplastic samples, representing a 19\% loss in biodiversity richness at the genus level. The data clearly shows a significant decrease in both richness and evenness at both phyla and genus level.

Alpha diversity, which measures variance within a sample decreased significantly after bioplastic degradation. The number of observed species was, on average, 2000 operational taxonomic units (OTU) in the control soil and this dropped to an average of just 957 OTUs (representing a 53\% decrease in biodiversity) within the bioplastic treated soil (Figure 7A). A Wilcox test showed that this change was statistically significant $(P=0.009)$. Beta diversity refers to the variance in microbial communities between samples, in this case between control soil and the bioplastic treated soil. UniFrac analysis is a phylogenetic-based beta diversity index that generates percentages of observed branch length unique to either sample. Unweighted UniFrac, which is a qualitative measurement, takes into consideration only the presence or absence of data. Weighted UniFrac is a quantitative measurement that takes into account relative abundance and branch length in the phylogenetic tree. The data from weighted UniFrac is more dominant-microorganism oriented. PCoA analysis of unweighted UniFrac (Figure 7B) also highlights the significant separation between the control soil samples and the bioplastic treated samples. The data collected show major changes in the soil microbiome in which the bioplastic degraded. Any disturbance caused to soil diversity can interfere with soil ecosystem functions such as decomposition and nutrient recycling. Given that the bioplastic is made of glycerol and collagen (both of which are easily metabolised), it is unsurprising that a wide range of bacteria could use them as growth substrates. The bioplastic would provide an easily degradable source of $\mathrm{C}, \mathrm{N}$ and $\mathrm{P}$, and so would allow the rapid population increase in fast growing (copiotrophic) bacteria. The significant shift in bacterial groups is likely due to these fast-growing bacteria resulting in niche exclusion of slow-growing bacteria, where they are outcompeted for space and growth-limiting nutrients such as iron, potassium, and phosphorus. Such shifts in bacterial community structure are also observed as a result of natural inputs of nutrients into the soil such as seasonal increases in leaf litter. Over time these temporary disturbances in the community structure tend to revert back to their state prior to the nutrient introduction [36].

Long-term microbiome analysis over several months is required to determine if the soil, after the disturbance in its stability, will naturally return to its original state from before the treatment. In a study by Adhikari et al. (2016) the effects of bioplastic degradation on the soil microbiome were studied after 28 days and 2 years and the authors concluded that there was no influence on soil diversity [37]. Overall degradation of bioplastic in that study was concluded to be low [37], therefore it is most likely that bioplastic had no effect on the soil diversity in contrast to the bioplastic used in the present study, which fully biodegraded in the soil. In a study by Qi et al. (2020) the same technique was used to assess plastic mulch films residues on soil microbiota, preforming DNA extractions and sequencing 16s rRNA, but with differences in experimental design [29]. At a phylum level, the composition of the soil in this study and in the study by Qi et al. (2020) were similar but not identical, and varied in the relative abundance of some of the phylum [29]. 


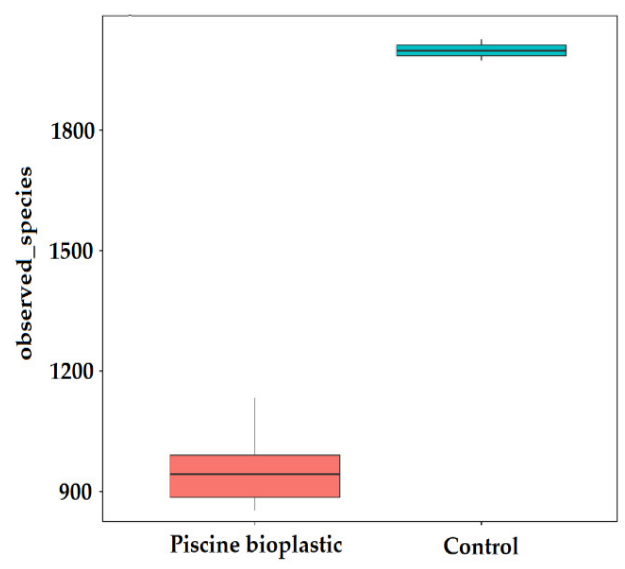

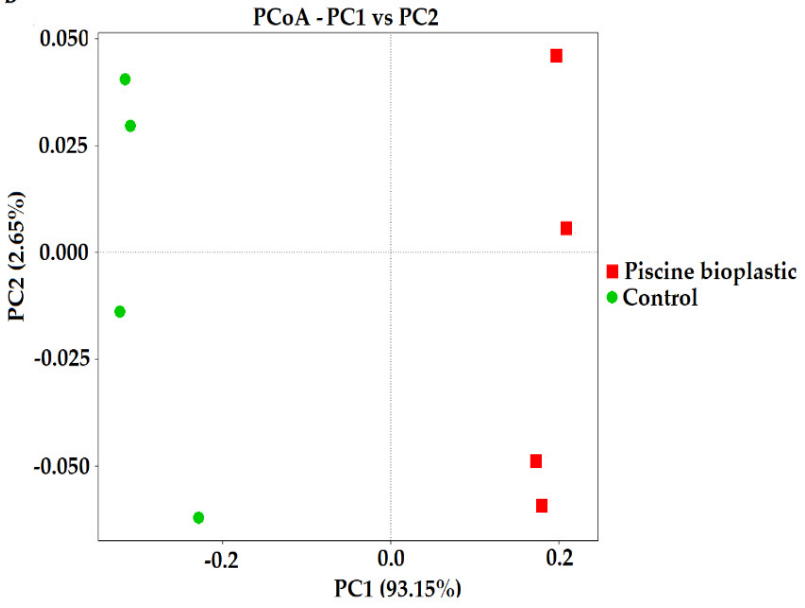

Figure 7. (A) Alpha diversity analysis based on number of observed species, (B) beta diversity analysis: PCoA based on weighted UniFract.

\section{Conclusions}

Bioplastic generated in this study has the potential to replace some single-use plastics, on its own or combined with other materials such as coatings. The bioplastic generated in this study fully degraded in moderate conditions $\left(20^{\circ} \mathrm{C}\right)$. The environmental assessment of microalgae showed increased growth due to release of nutrients, which can lead to eutrophication if bioplastic disposal is mismanaged. Piscine bioplastic lowered the nematode reproduction numbers, but these were not statistically significant. Two plant species, cress and mustard, experienced some negative effects on seed germination when treated with some of the bioplastics. A clear reduction in soil microbial biodiversity was also recorded in soil treated with piscine bioplastics. All of these negative effects are likely to be short-term and localised. The benefits of fully biodegradable bioplastic that will not accumulate in the environment like petroleum-based plastics are likely to significantly outweigh any of the short-term effects.

All assessments carried out in this study were in simulated natural conditions in laboratory settings. The assessments focused on specific indicators but did not take into account seasonal or weather variations, which is a limitation of the study and can have a significant impact on the biodegradation of the bioplastic [38]. Both methods have advantages and limitations, in laboratory settings, conditions such as temperature and $\mathrm{pH}$ can be controlled. Biodegradation in a natural environment is more unpredictable, but the results are more realistic. To fully assess these negative effects and their duration, long-term assessment in the natural environment would be required to provide more accurate and realistic data.

Further, it is crucial to establish the overall sustainability of this bioplastic by using life cycle assessment (LCA). Methodologies used in LCA take into account energy and materials used in a process or product as well as waste and emissions released into the environment. To measure energy consumption most methods use the first law of thermodynamics and the exergy method, which follows an LCA approach, is based on upper limit energy consumption for a reversible process to estimate energy for a non-reversible process. The exergy method takes into account resource depletion; therefore, it is a good indicator of product or process sustainability [39]. Moving away from petroleum-based plastic is only the first step. Studies that investigate the sustainability and environmental impact of newly developed plastic alternatives are crucial and must become the focus in the bioplastic industry. Such studies will allow the implementation of efficient legislation and disposal systems for newly developed materials. 
Author Contributions: Conceptualisation, A.C.N.; methodology, A.C.N., K.G. and T.K.D.; investigation, M.M.; writing—original draft preparation, M.M.; writing—review and editing, A.C.N., T.K.D., D.C. and K.G.; supervision, A.C.N., D.C. and K.G.; project administration, M.M., A.C.N., D.C. and K.G.; funding acquisition, A.C.N. All authors have read and agreed to the published version of the manuscript.

Funding: The research conducted in this publication was jointly funded by the Irish Research Council under grant number GOIPG/2021/505, and by Institute of Technology Carlow President Award Fellowship grant number PES1300. The APC was funded by Institute of Technology Carlow.

Institutional Review Board Statement: Not applicable.

Informed Consent Statement: Not applicable.

Data Availability Statement: Data available in NCBI database, bioproject no. PRJNA759397 and accession numbers SRR15698719 to SRR15698726.

Conflicts of Interest: The authors declare no conflict of interest.

\section{References}

1. Geyer, R.; Jambeck, J.; Law, K. Production, use, and fate of all plastics ever made. Sci. Adv. 2017, 3, e1700782. [CrossRef] [PubMed]

2. Jambeck, J.; Geyer, R.; Wilcox, C.; Siegler, T.; Perryman, M.; Andrady, A.; Narayan, R.; Law, K. Plastic waste inputs from land into the ocean. Science 2015, 347, 768-771. [CrossRef]

3. Castañeda, R.; Avlijas, S.; Simard, M.; Ricciardi, A. Microplastic pollution in St. Lawrence River sediments. Can. J. Fish. Aquat. Sci. 2014, 71, 1767-1771. [CrossRef]

4. Romeo, T.; Pietro, B.; Pedà, C.; Consoli, P.; Andaloro, F.; Fossi, M. First evidence of presence of plastic debris in stomach of large pelagic fish in the Mediterranean Sea. Mar. Pollut. Bull. 2015, 95, 358-361. [CrossRef]

5. Gall, S.; Thompson, R. The impact of debris on marine life. Mar. Pollut. Bull. 2015, 92, 170-179. [CrossRef] [PubMed]

6. Ncube, L.; Ude, A.; Ogunmuyiwa, E.; Zulkifli, R.; Beas, I. An Overview of Plastic Waste Generation and Management in Food Packaging Industries. Recycling 2021, 6, 12. [CrossRef]

7. Qu, S.; Guo, Y.; Ma, Z.; Chen, W.; Liu, J.; Liu, G.; Wang, Y.; Xu, M. Implications of China's foreign waste ban on the global circular economy. Resour. Conserv. Recycl. 2019, 144, 252-255. [CrossRef]

8. Kaza, S.; Bhada-Tata, P.; Ionkova, K.; Van Woerden, F.; Yao, L. What a waste 2.0.A Global Snapshot of Solid Waste Management to 2050, World Bank [pdf]. 2018. Available online: https:/ / openknowledge.worldbank.org/handle/10986/30317 (accessed on 1 September 2021).

9. European Commission. EU Plastic Strategy. Available online: https:/ / ec.europa.eu/commission/news/eu-plastics-strategy-20 18-nov-20_en (accessed on 2 April 2021).

10. Fakhouri, F.; Maria Martelli, S.; Canhadas Bertan, L.; Yamashita, F.; Innocentini Mei, L.; Collares Queiroz, F. Edible films made from blends of manioc starch and gelatin-Influence of different types of plasticizer and different levels of macromolecules on their properties. LWT 2012, 49, 149-154. [CrossRef]

11. Abe, M.; Branciforti, M.; Brienzo, M. Biodegradation of Hemicellulose-Cellulose-Starch-Based Bioplastics and Microbial Polyesters. Recycling 2021, 6, 22. [CrossRef]

12. Neves, A.; Moyne, M.; Eyre, C.; Casey, B. Acceptability and Societal Impact of the Introduction of Bioplastics as Novel Environmentally Friendly Packaging Materials in Ireland. Clean Technol. 2020, 2, 127-143. [CrossRef]

13. Narancic, T.; Cerrone, F.; Beagan, N.; O'Connor, K. Recent Advances in Bioplastics: Application and Biodegradation. Polymers 2020, 12, 920 .

14. Fakhouri, F.; Costa, D.; Yamashita, F.; Martelli, S.; Jesus, R.; Alganer, K.; Collares-Queiroz, F.; Innocentini-Mei, L. Comparative study of processing methods for starch/gelatin films. Carbohydr. Polym. 2013, 95, 681-689. [CrossRef]

15. Ramos, M.; Valdés, A.; Beltrán, A.; Garrigós, M. Gelatin-Based Films and Coatings for Food Packaging Applications. Coatings 2016, 6, 41. [CrossRef]

16. Wasswa, J.; Tang, J.; Gu, X. Utilization of Fish Processing By-Products in the Gelatin Industry. Food Rev. Int. 2007, 23, 159-174. [CrossRef]

17. Huang, T.; Tu, Z.; Shangguan, X.; Wang, H.; Zhang, L.; Sha, X. Rheological and structural properties of fish scales gelatin: Effects of conventional and ultrasound-assisted extraction. Int. J. Food Prop. 2017, 20, S1210-S1220. [CrossRef]

18. Boyle, S.; Kakouli-Duarte, T. The effects of chromium VI on the fitness and on the $\beta$-tubulin genes during in vivo development of the nematode Steinernema feltiae. Sci. Total Environ. 2008, 404, 56-67. [CrossRef]

19. Mroczkowska, M.; Culliton, D.; Germaine, K.; Neves, A. Comparison of Mechanical and Physicochemical Characteristics of Potato Starch and Gelatine Blend Bioplastics Made with Gelatines from Different Sources. Clean Technol. 2021, 3, 424-436. [CrossRef]

20. Klebercz, O. Manual of the Laboratory Practices; Department of Applied Biotechnology and Food Science, Environmental Toxicology: Budapest, Hungary, 2013. Available online: http://envirotox.hu/wp-content/uploads/2017/10/Laboratory_practices_manual_ Environmental_Tox.pdf (accessed on 20 July 2021). 
21. International Organization for Standardization. ISO 17556:2012 Plastics_Determination of the Ultimate Aerobic Biodegradability of Plastic Materials in Soil by Measuring the Oxygen Demand in Respirometer or the Amount of Carbon Dioxide Evolved; ISO: Geneva, Switzerland, 2012.

22. White, G. A Method for Obtaining Infective Nematode Larvae from Cultures. Science 1927, 66, 302-303. [CrossRef]

23. Nur Hanani, Z.; Roos, Y.; Kerry, J. Use of beef, pork and fish gelatin sources in the manufacture of films and assessment of their composition and mechanical properties. Food Hydrocoll. 2012, 29, 144-151. [CrossRef]

24. Neidhardt, K.; Wasmuth, T. PRM157 Methodological Challenges of IQWiG's Efficiency Frontier Concept Elicited by Multiple Patient-Relevant Endpoints-Why Prioritization of Endpoints Cannot Be Avoided. Value Health 2012, 15, A489. [CrossRef]

25. Sforzini, S.; Oliveri, L.; Chinaglia, S.; Viarengo, A. Application of Biotests for the Determination of Soil Ecotoxicity after Exposure to Biodegradable Plastics. Front. Environ. Sci. 2016, 4, 68. [CrossRef]

26. Bongers, T.; Ferris, H. Nematode community structure as a bioindicator in environmental monitoring. Trends Ecol. Evol. 1999, 14, 224-228. [CrossRef]

27. Gómez-Guillén, M.; Turnay, J.; Fernández-Díaz, M.; Ulmo, N.; Lizarbe, M.; Montero, P. Structural and physical properties of gelatin extracted from different marine species: A comparative study. Food Hydrocoll. 2002, 16, 25-34. [CrossRef]

28. Hazir, S.; Stock, S.; Kaya, H.; Koppenhöfer, A.; Keskin, N. Developmental Temperature Effects on Five Geographic Isolates of the Entomopathogenic Nematode Steinernema feltiae (Nematoda: Steinernematidae). J. Invertebr. Pathol. 2001, 77, 243-250. [CrossRef] [PubMed]

29. Qi, Y.; Ossowicki, A.; Yang, X.; Huerta Lwanga, E.; Dini-Andreote, F.; Geissen, V.; Garbeva, P. Effects of plastic mulch film residues on wheat rhizosphere and soil properties. J. Hazard. Mater. 2020, 387, 121711. [CrossRef] [PubMed]

30. Bosker, T.; Bouwman, L.; Brun, N.; Behrens, P.; Vijver, M. Microplastics accumulate on pores in seed capsule and delay germination and root growth of the terrestrial vascular plant Lepidium sativum. Chemosphere 2019, 226, 774-781. [CrossRef] [PubMed]

31. Zhang, Y.; Smith, P.; Maximova, S.; Guiltinan, M. Application of glycerol as a foliar spray activates the defence response and enhances disease resistance of Theobroma cacao. Mol. Plant Pathol. 2015, 16, 27-37. [CrossRef]

32. Balestri, E.; Menicagli, V.; Ligorini, V.; Fulignati, S.; Raspolli Galletti, A.; Lardicci, C. Phytotoxicity assessment of conventional and biodegradable plastic bags using seed germination test. Ecol. Indic. 2019, 102, 569-580. [CrossRef]

33. Bergey, D.; Whitman, W.; De Vos, P.; Garrity, G.; Jones, D. Bergey's manual of systematic bacteriology. In The Firmicutes; Springer: New York, NY, USA, 2009.

34. Kielak, A.; Barreto, C.; Kowalchuk, G.; van Veen, J.; Kuramae, E. The Ecology of Acidobacteria: Moving beyond Genes and Genomes. Front. Microbiol. 2016, 7, 744. [CrossRef] [PubMed]

35. Zhang, Y.; Cong, J.; Lu, H.; Li, G.; Qu, Y.; Su, X.; Zhou, J.; Li, D. Community structure and elevational diversity patterns of soil Acidobacteria. J. Environ. Sci. 2014, 26, 1717-1724. [CrossRef]

36. Landesman, W.; Freedman, Z.; Nelson, D. Seasonal, sub-seasonal and diurnal variation of soil bacterial community composition in a temperate deciduous forest. FEMS Microbiol. Ecol. 2019, 95, fiz002. [CrossRef] [PubMed]

37. Adhikari, D.; Mukai, M.; Kubota, K.; Kai, T.; Kaneko, N.; Araki, K.; Kubo, M. Degradation of Bioplastics in Soil and Their Degradation Effects on Environmental Microorganisms. J. Agric. Chem. Environ. 2016, 5, 23-34. [CrossRef]

38. Ahimbisibwe, M.; Banadda, N.; Seay, J.; Nabuuma, B.; Atwijukire, E.; Wembabazi, E.; Nuwamanya, E. Influence of Weather and Purity of Plasticizer on Degradation of Cassava Starch Bioplastics in Natural Environmental Conditions. J. Agric. Chem. Environ. 2019, 8, 237-250. [CrossRef]

39. Rosen, M. Environmental sustainability tools in the biofuel industry. Biofuel Res. J. 2018, 5, 751-752. [CrossRef] 